\title{
Biologia e tabela de vida de fertilidade de Agrotis ipsilon em dieta artificial
}

\author{
Flavia de Moura Manoel Bento(1), Sandra Regina Magro(2), Priscila Fortes ${ }^{(1)}$, Neide Graciano Zério(1) \\ e José Roberto Postali Parra(1)
}

\begin{abstract}
(1)Escola Superior de Agricultura Luiz de Queiroz, Dep. de Entomologia, Fitopatologia e Zoologia Agrícola, Av. Pádua Dias, no 11, Caixa Postal 9 , CEP 13418-900 Piracicaba, SP. E-mail: flaviam@esalq.usp.br, pfortes@esalq.usp.br, ngzerio@esalq.usp.br, jrpparra@esalq.usp.br (2)Universidade Camilo Castelo Branco, Campus Fernandópolis, Estrada Projetada F1, s/no, Fazenda Santa Rita, CEP 15600-000 Fernandópolis, SP. E-mail: sandra.magro@gmail.com
\end{abstract}

\begin{abstract}
Resumo - O objetivo deste trabalho foi desenvolver uma dieta artificial para criação de Agrotis ipsilon em laboratório com base em parâmetros biológicos e na tabela de vida de fertilidade. A dieta artificial utilizada continha feijão, caseína, proteína de soja, levedura e germe de trigo como fontes protéicas. Os parâmetros biológicos duração e viabilidade das fases larval e pupal, peso de pupas, de ambos os sexos, com 24 horas de idade, razão sexual, longevidade dos adultos, período de pré-oviposição e número de ovos produzidos por fêmea e a tabela de vida de fertilidade foram avaliados. Foram observados seis ínstares larvais com duração de 25,4 dias e viabilidade de $93 \%$. A duração da fase pupal foi de 12,4 dias e viabilidade de $96 \%$. A viabilidade de ciclo total foi $72 \%$. O peso de pupas foi $387 \mathrm{mg}$ (machos) e $484 \mathrm{mg}$ (fêmeas). A razão sexual foi 0,46. O período de pré-oviposição foi de um dia, com 1.806 ovos por fêmea. Na tabela de vida verificou-se que a taxa líquida de reprodução e a razão finita de aumento foram 616,9 e 1,14, respectivamente. A dieta artificial é adequada à manutenção da criação de A. ipsilon, em laboratório.
\end{abstract}

Termos para indexação: lagarta-rosca, criação, praga de solo, Noctuidae.

\section{Biology and fertility life table of Agrotis ipsilon on artificial diet}

\begin{abstract}
The objective of this work was to develop an artificial diet to rear Agrotis ipsilon in laboratory using biological parameters and fertility life table. The artificial diet was prepared with bean, casein, soybean protein, yeast and wheat germ as protein sources. The biological aspects duration and viability of larval and pupal stages, pupal weight, sex ratio, life span of adults, preoviposition period, egg laying capacity and fertility life table were evaluated. Six larval instars were observed comprising larval duration of 28,4 days and $93 \%$ of viability mean pupal duration of 12,4 days and viability of $96 \%$. The total viability of the life cycle was $72 \%$. The pupae weight was $387 \mathrm{mg}$ for males and $484 \mathrm{mg}$ for females. The sex ratio was 0,46 and the preoviposition period lasted one day and egg laying was 1,806 eggs per female. The net reproductive rate per generation and increase finite rate were 616,9 and 1,14, respectively. Artificial diet is adequate for rearing A. ipsilon in laboratory.
\end{abstract}

Index terms: black cutworm, rearing, soil pest, Noctuidae.

\section{Introdução}

As lagartas-roscas pertencentes ao gênero Agrotis constituem um importante grupo de insetos-praga, devido, principalmente, aos prejuízos causados a grande número de plantas cultivadas e à sua vasta distribuição geográfica (Vendramim et al., 1982). Agrotis ipsilon (Hufnagel, 1767) é a principal espécie de lagarta-rosca referida no Brasil e é um inseto polífago, que ataca principalmente hortaliças como: solanáceas, curcubitáceas e crucíferas. Pode atacar também outras espécies de diferentes famílias de plantas, em culturas como as de milho e soja e cultivos de subsistência como feijoeiro (Silva et al., 1968; Link \& Pedrolo, 1987).

Os prejuízos são causados pela lagarta que corta plântulas de até $10 \mathrm{~cm}$ de altura (Gallo et al., 2002). A. ipsilon ocorre principalmente em locais mais úmidos e com grande capacidade de multiplicação, pois uma fêmea chega a colocar mais de mil ovos (Santos \& Nakano, 1982). Trata-se de um inseto de difícil controle, devido à dificuldade de visualização no campo, pelo seu hábito noturno, destruindo plantas recém-germinadas (Link \& Pedrolo, 1987). 
Atualmente, o controle de A. ipsilon e outras espécies de lagartas-roscas é realizado de forma química, às vezes, utilizando-se produtos de alta toxicidade. $O$ controle tem que ser curativo, dirigindo-se o jato de pulverização para a base da planta ou tratando-se as sementes, mudas ou o sulco de plantio com piretróides ou produtos de ação sistêmica (Gallo et al., 2002).

Existem poucos estudos sobre esse inseto em virtude da dificuldade da sua criação em dietas naturais, com exceção do trabalho de Santos \& Nakano (1982), que conseguiram criá-lo em folhas de couve. Essa técnica, no entanto, nem sempre supre a necessidade de estudos que requerem muitos insetos e, consequientemente, exige mão-de-obra pela necessidade de substituição e reposição diária de alimento. $\mathrm{O}$ desenvolvimento da dieta permite a condução de estudos de métodos alternativos de controle dessa praga.

O objetivo deste trabalho foi desenvolver uma dieta artificial para a criação de A. ipsilon em laboratório, com base em parâmetros biológicos e em tabela de vida de fertilidade.

\section{Material e Métodos}

O trabalho foi desenvolvido no Laboratório de Biologia de Insetos do Departamento de Entomologia, Fitopatologia e Zoologia Agrícola da Escola Superior de Agricultura Luiz de Queiroz, com temperatura de $26 \pm 1^{\circ} \mathrm{C}$, umidade relativa do ar $70 \pm 10 \%$ e fotófase de 14 horas. As lagartas de A. ipsilon foram coletadas em campo, em Santa Cruz do Sul, RS, na cultura de fumo.

Na criação em dieta artificial, foram utilizados tubos de vidro de 2,5 de diâmetro x $8,5 \mathrm{~cm}$ de altura, tampados com algodão hidrófobo e previamente esterilizados em estufa a $180^{\circ} \mathrm{C}$. A dieta artificial (adaptada de Greene et al., 1976) foi composta de: $3.400 \mathrm{~mL}$ de água; $46 \mathrm{~g}$ de ágar; $250 \mathrm{~g}$ de feijão-branco; $200 \mathrm{~g}$ de germe de trigo; $75 \mathrm{~g}$ de caseína; $125 \mathrm{~g}$ de levedura de cerveja; $12 \mathrm{~g}$ de ácido ascórbico; $20 \mathrm{~mL}$ de mistura vitamínica Vanderzant; $250 \mathrm{~g}$ de tetraciclina; $12 \mathrm{~mL}$ de formaldeído (40\%); $10 \mathrm{~mL}$ de metil parahidroxibenzoato (nipagin); $6 \mathrm{~g}$ de ácido sórbico; $100 \mathrm{~g}$ de proteína de soja. O preparo da dieta artificial e a técnica de criação foram realizados de acordo com Parra (2001). Em tubos contendo $10 \mathrm{~mL}$ da dieta artificial, foram avaliadas 160 lagartas, mantidas individualmente, após a eclosão.

$\mathrm{Na}$ avaliação do número de ínstares, foram separados e numerados 30 tubos, com uma lagarta em cada um, sendo utilizada uma ocular micrométrica (Wild MM 5235) acoplada a um microscópio estereoscópico, para medições diárias das cápsulas cefálicas. A determinação do número de ínstares foi realizada no programa MOBAE (Modelos Bioestatísticos Aplicados a Entomologia) (Haddad et al., 1999), com base na regra de Dyar (Parra \& Haddad, 1989).

Os parâmetros biológicos avaliados foram: duração e viabilidade das fases larval e pupal, peso de pupas, de ambos os sexos, com 24 horas de idade, razão sexual

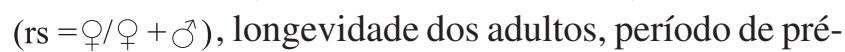
oviposição e número de ovos produzidos por fêmea. $\mathrm{Na}$ avaliação do período embrionário e sua viabilidade, foram separadas alíquotas com 30 ovos (da segunda postura de cada fêmea) e mantidas nas mesmas condições descritas anteriormente, em placas de Petri sobre papel-filtro umedecido.

Os adultos, separados em casais, foram colocados em gaiolas de PVC com $10 \mathrm{~cm}$ de diâmetro e $20 \mathrm{~cm}$ de altura, revestidos com papel sulfite, sobre placa de Petri forrada com papel-filtro. O alimento oferecido foi solução de mel a 10\%, embebida em rolo dental; as gaiolas de PVC foram tampadas com tecido do tipo "voile", que serviu também como substrato de oviposição. O tecido, contendo os ovos, foi trocado diariamente para contagem dos ovos, realizando-se observações até a morte dos adultos de ambos os sexos.

A partir dos dados biológicos obtidos, elaborou-se tabela de vida de fertilidade, segundo Silveira Neto et al. (1976), determinando-se: taxa líquida de reprodução (Ro); tempo médio de uma geração (T); taxa intrínseca de aumento $\left(r_{m}\right)$ e razão finita de aumento $(\lambda)$. Foram estudados 25 casais para confecção da tabela de vida.

\section{Resultados e Discussão}

A duração da fase embrionária de A. ipsilon foi, em média, de 3,3 dias com viabilidade de $81 \%$. As fases de desenvolvimento larval e pupal apresentaram duração média de 25,4 e 12,4 dias, respectivamente, com viabilidades de 93 e $96 \%$. Assim, a duração e viabilidade do ciclo total (ovo-adulto) foram, respectivamente, de 41,1 dias e $72 \%$. Esses dados foram próximos aos observados por Nag \& Nath (1993) para duração das fases e ciclo total de A. ipsilon, quando criada em dieta à base de germe de trigo e caseína. A viabilidade do ciclo total observada foi inferior à obtida por Wu et al. (1992), que foi de $80 \%$ para outra espécie de lagartarosca, A. segetum Schiff, criada em dieta artificial com germe de trigo e Chenopodium album. 
No desenvolvimento larval de A. ipsilon, foram observados seis ínstares para $100 \%$ das lagartas, e a média de crescimento foi de $1,62\left(\mathrm{R}^{2}=100 \%\right)$, valor que se encontra dentro do intervalo de variação de $1,1 \mathrm{e}$ 1,9 estabelecido por Dyar (1890) (Figura 1). Esses valores também foram observados por Santos \& Nakano (1982) e Santos \& Shields (1998). Vendramim et al. (1982) também observaram seis ínstares para $100 \%$ das lagartas de A. subterranea (Fabricius) desenvolvidas em dietas natural e artificial. O peso médio das pupas foi de $484 \mathrm{mg}$ para fêmeas e de $387 \mathrm{mg}$ para machos, com respectivas durações de 12,6 e 12,3 dias. A razão sexual foi de 0,46 e, portanto, de 1 macho: 1 fêmea.

As longevidades médias de machos e fêmeas foram semelhantes, sendo em média 13,63 e 13,08 dias, respectivamente, com variação de 10 a 17 dias. As posturas foram distribuídas durante toda a fase adulta, e $80 \%$ do total dos ovos foram depositados até o oitavo dia.

As fêmeas apresentaram período de pré-oviposição de um dia, com média de $1.806,5$ ovos por fêmea (variação de 523 a 3.124 ovos), valor considerado alto, se comparado aos registrados por Nag \& Nath (1993), que observaram variação de 333 a 748 ovos por fêmea, de insetos provenientes também de dieta artificial, à base de germe de trigo.

A taxa líquida de reprodução (Ro) indicou que a população de $A$. ipsilon pode aumentar 616,9 vezes por geração. Embora este trabalho tenha sido conduzido por apenas uma geração de laboratório, o alto valor de Ro obtido indica que houve rápida adaptação à dieta artificial pois, segundo Parra (2001), os insetos podem demorar

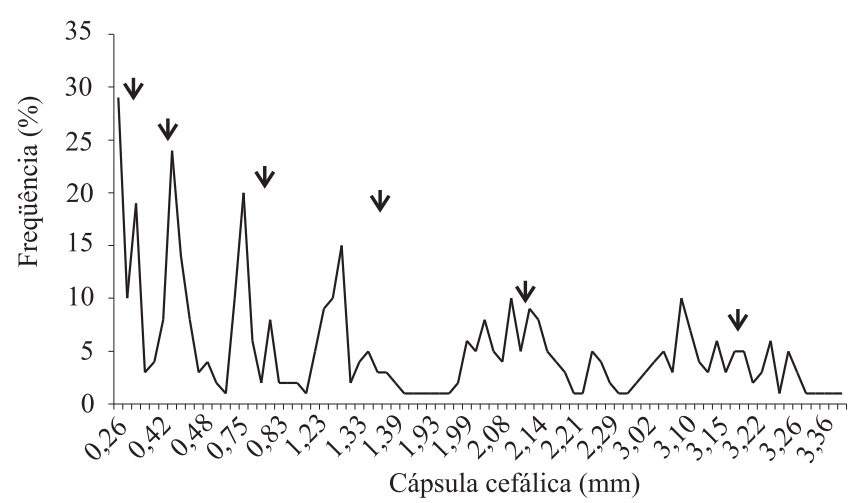

Figura 1. Freqüência das medições das cápsulas cefálicas de Agrotis ipsilon durante o desenvolvimento larval em dieta artificial. Temperatura: $26 \pm 1^{\circ} \mathrm{C}$; umidade relativa do ar: $70 \pm 10 \%$; fotófase: 14 horas. As setas indicam os ínstares. de cinco a sete gerações para se adaptarem a uma dieta artificial. O tempo médio de uma geração $(\mathrm{T})$ foi de aproximadamente 48 dias, em condições de temperatura, umidade relativa e fotófase constantes. A taxa intrínseca de crescimento $\left(\mathrm{r}_{\mathrm{m}}\right)$, característica da espécie, foi de 0,133 , e a razão finita de aumento $(\lambda)$, ou seja, o número de fêmeas adicionadas à população por fêmea que dará fêmea, foi de 1,14.

A taxa máxima de aumento populacional ocorreu no $50^{\mathrm{o}}$ dia, que corresponde ao ponto de encontro da fertilidade específica $(\mathrm{mx})$ e da taxa de sobrevivência (lx) (Figura 2). De acordo com os valores biológicos obtidos, a dieta artificial é adequada para manutenção contínua de $A$. ipsilon, pois os resultados estão próximos aos obtidos por Santos \& Nakano (1982) em dieta natural e por Nag \& Nath (1993) e Santos \& Shields (1998) em dietas artificiais. Trata-se de uma dieta rica em proteínas, feijão, germe de trigo, caseína, levedura e proteína de soja, em proporções balanceadas com os carboidratos oferecidos. Embora a viabilidade do ciclo total obtida (72\%) esteja abaixo dos $75 \%$ preconizados por Singh (1983), os adultos obtidos foram normais e colocaram uma quantidade de ovos (1.806 ovos) superior à citada por Santos \& Nakano (1982).

Apesar de já existirem referências internacionais (Mangat, 1970; Reese \& Field, 1986; Hendrix et al., 1991; Nag \& Nath, 1993; Santos \& Shields, 1998), este trabalho é a primeira referência de uma dieta artificial para a criação de A. ipsilon no Brasil.

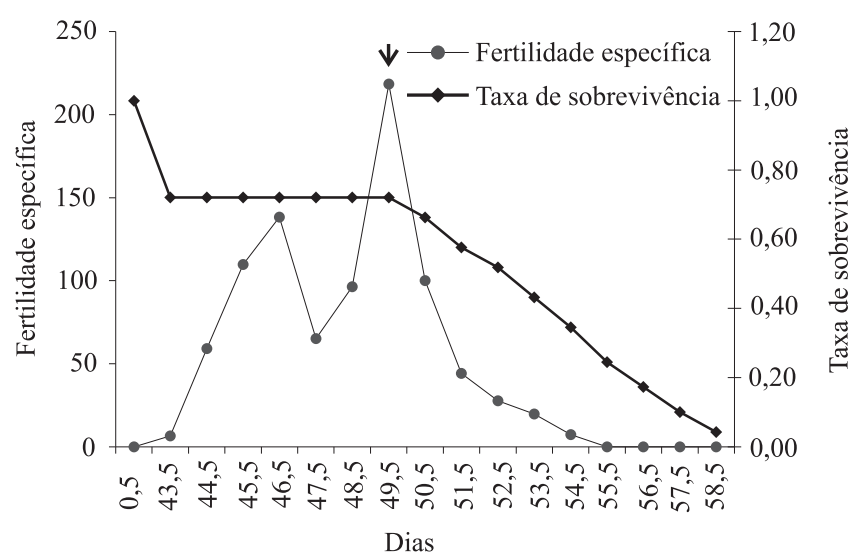

Figura 2. Relação entre fertilidade específica (mx) e taxa de sobrevivência (lx) de Agrotis ipsilon criada em dieta artificial. A seta indica a taxa máxima de aumento. Temperatura: $26 \pm 1^{\circ} \mathrm{C}$; umidade relativa do ar: $70 \pm 10 \%$; fotófase: 14 horas. 


\section{Conclusão}

A dieta artificial é adequada para a manutenção da criação de Agrotis ipsilon em laboratório.

\section{Agradecimentos}

Ao Dr. Jerson Carus Guedes, da Universidade Federal de Santa Maria, RS, pelo disponibilização dos insetos.

\section{Referências}

DYAR, H.G. The number of molts of lepidopterous larvae. Psyche, v.5, p.420-422, 1890.

GALLO, D.; NAKANO, O.; SILVEIRA NETO, S.; CARVALHO, R.P.L.; BAPTISTA, G.C.; BERTI FILHO, E.; PARRA, J.R.P.; ZUCCHI, R.A.; ALVES, S.B.; VENDRAMIM, J.D.; MARCHINI, L.C.; LOPES, J.R.S.; OMOTO, C. Entomologia agrícola. Piracicaba: Fealq, 2002. 920p.

GREENE, G.L.; LEPPLA, N.C.; DICKERSON, W.A. Velvetbean catterpillar: a rearing procedure and artificial medium. Journal of Economic Entomology, v.69, p.487-488, 1976.

HADDAD, M.L.; PARRA, J.R.P.; MORAES, R.C.B. Métodos para estimar os limites térmicos inferior e superior de desenvolvimento de insetos. Piracicaba: Fealq, 1999. 29p.

HENDRIX, W.H.; GUNNARSON, D.F.; SHOWERS, W.B. Modification of a meridic diet for rearing black cutworm (Lepidoptera: Noctuidae) larvae. Journal of the Kansas Entomological Society, v.64, p.45-50, 1991.

LINK, D.; PEDROLO, S.S. Aspectos biológicos de Agrotis ipsilon (Hufnagel, 1767) em Santa Maria - RS. Revista de Ciências Rurais, v.17, p.309-317, 1987.

MANGAT, B.S. Rearing the black cutworm in the laboratory. Journal of Economic Entomology, v.63, p.1325-1326, 1970.
NAG, A.J.; NATH, P. Biology of cutworm Agrotis ipsilon (Hufn.) on some natural and an artificial food. Naturalia São Paulo, v.18, p.57-66, 1993.

PARRA, J.R.P. Técnicas de criação de insetos para programas de controle biológico. Piracicaba: Fealq, 2001. 134p.

PARRA, J.R.P.; HADDAD, M.L. Determinação do número de ínstares de insetos. Piracicaba: Fealq, 1989. 49p.

REESE, J.C.; FIELD, M.D. Defenses against insect attack in susceptible plants - Black cutworm (Lepidoptera: Noctuidae) growth on corn seedlings and artificial diet. Annals of the Entomological Society of America, v.79, p.372-376, 1986.

SANTOS, H.R.; NAKANO, O. Dados biológicos sobre a lagartarosca Agrotis ipsilon (Hufnagel, 1767) (Lepidoptera, Noctuidae). Anais da Sociedade Brasileira Entomológica do Brasil, v.11, p.33-48, 1982.

SANTOS, L.; SHIELDS, E.J. Temperature and diet effect on black cutworm (Lepidoptera: Noctuidae) larval development. Journal of Economic Entomology, v.91, p.267-273, 1998.

SILVA, A.G.A.; GONÇALVES, C.R.; GALVÃO, D.M.; GONÇALVES, A.J.L.; GOMES J.; SILVA, M.N.; SIMONI, L. de. Quarto catalogo dos insetos que vivem nas plantas do Brasil, seus parasitos e predadores. Rio de Janeiro: Ministério da Agricultura, 1968. 622p. Parte II, $2^{\circ}$ tomo.

SILVEIRANETO, S.; NAKANO, O.; BARBIN, D.; VILLANOVA, N.D. Manual de ecologia dos insetos. São Paulo: Ceres, 1976. $419 \mathrm{p}$.

SINGH, P. A general purpose laboratory diet mixture for rearing insects. Insect Science and its Application, v.4, p.357-362, 1983.

VENDRAMIM, J.D.; FERRAZ, M.C.V.D.; PARRA, J.R.P. Biologia comparada de Agrotis subterranea (F) em meios natural e artificial. O Solo, v.74, p.76-80, 1982.

WU, K.J.; GONG, P.Y.; LI, X.Z. An artificial diet and a method for rearing the turnip moth, Agrotis segetum Schiff (Lepidoptera: Noctuidae). Bulletin of the Institute of Zoology, Academia Sinica, v.31, p.121-129, 1992.

$\overline{\text { Recebido em } 11 \text { de abril de } 2007 \text { e aprovado em } 3 \text { de setembro de } 2007}$ 